University of Wollongong

Research Online

Australian Institute for Innovative Materials -

Papers

Australian Institute for Innovative Materials

$1-1-2016$

Systematic elongation of thienyl linkers and their effect on optical and electrochemical properties in carbazole-BODIPY donor-acceptor systems

\author{
Alina Brzeczek \\ University of Wollongong \\ Katarzyna Piwowar \\ University of Wollongong \\ Wojciech Domagala \\ Silesian University of Technology \\ Mikotaj M. Mikotajczyk \\ Silesian University of Technology, Wroclaw University of Technology \\ Krzysztof Walczak \\ Silesian University of Technology
}

See next page for additional authors

Follow this and additional works at: https://ro.uow.edu.au/aiimpapers

Part of the Engineering Commons, and the Physical Sciences and Mathematics Commons

Research Online is the open access institutional repository for the University of Wollongong. For further information contact the UOW Library: research-pubs@uow.edu.au 


\title{
Systematic elongation of thienyl linkers and their effect on optical and electrochemical properties in carbazole-BODIPY donor-acceptor systems
}

\author{
Abstract \\ Synthesis, spectral and electrochemical properties of a series of new panchromatic BODIPY donor- \\ acceptor-donor derivatives, comprising carbazole conjugated with systematically elongated framework by \\ thiophene-based linkers were investigated. It has been found that elongation of the $\pi$-system with one \\ thiophene unit shifts the spectra toward near infrared, while incorporation of next thiophene derivatives \\ has only limited influence on the lowest energy transition, causing no further shift of absorption maxima. \\ Elongation of $\pi$-conjugation of the donor arm tunes the electron properties, influencing the ionization \\ potential (IP) and electron affinity (EA) values of the molecules. The experimental results are supported \\ by quantum chemical computations revealing that electron density of SOMO orbital is low at the \\ 3-positions of terminal carbazole units in BODIPY push-pull oligomers while elongating their backbone, \\ thus preventing them to undergo electrochemical polymerization giving reversibly $p$ - and $n$-dopable \\ products. Presented study tests the influence and limitations of incorporation of electron-rich \\ substituents for designing panchromatic BODIPY systems.
}

\section{Keywords}

acceptor, systems, bodipy, carbazole, properties, electrochemical, optical, effect, donor, their, systematic, linkers, thienyl, elongation

\section{Disciplines}

Engineering | Physical Sciences and Mathematics

\section{Publication Details}

Brzeczek, A., Piwowar, K., Domagala, W., Mikotajczyk, M. M., Walczak, K. \& Wagner, P. (2016). Systematic elongation of thienyl linkers and their effect on optical and electrochemical properties in carbazoleBODIPY donor-acceptor systems. RSC Advances: an international journal to further the chemical sciences, 6 (43), 36500-36509.

\section{Authors}

Alina Brzeczek, Katarzyna Piwowar, Wojciech Domagala, Mikotaj M. Mikotajczyk, Krzysztof Walczak, and Pawel W. Wagner 


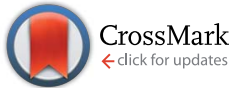

Cite this: RSC Adv., 2016, 6, 36500

Received 25th February 2016

Accepted 5th April 2016

DOI: $10.1039 / c 6 r a 04984 b$

www.rsc.org/advances

\section{Systematic elongation of thienyl linkers and their effect on optical and electrochemical properties in carbazole-BODIPY donor-acceptor systems $\uparrow$}

\author{
Alina Brzeczek, ${ }^{\text {ab }}$ Katarzyna Piwowar, ${ }^{\text {ab }}$ Wojciech Domagala, ${ }^{b}$ \\ Mikołaj M. Mikołajczyk, ${ }^{\text {bc }}$ Krzysztof Walczak ${ }^{b}$ and Pawel Wagner*a
}

Synthesis, spectral and electrochemical properties of a series of new panchromatic BODIPY donoracceptor-donor derivatives, comprising carbazole conjugated with systematically elongated framework by thiophene - based linkers were investigated. It has been found that elongation of the $\pi$-system with one thiophene unit shifts the spectra toward near infrared, while incorporation of next thiophene derivatives has only limited influence on the lowest energy transition, causing no further shift of absorption maxima. Elongation of $\pi$-conjugation of the donor arm tunes the electron properties, influencing the ionization potential (IP) and electron affinity (EA) values of the molecules. The experimental results are supported by quantum chemical computations revealing that electron density of SOMO orbital is low at the 3-positions of terminal carbazole units in BODIPY push-pull oligomers while elongating their backbone, thus preventing them to undergo electrochemical polymerization giving reversibly $\mathrm{p}$ - and $\mathrm{n}$-dopable products. Presented study tests the influence and limitations of incorporation of electron - rich substituents for designing panchromatic BODIPY systems.

\section{Introduction}

NIR emitting organic molecules can find application in optoelectronics: telecommunication or optical signalling and nightvision devices. Also, radiation with energy above $650 \mathrm{~nm}$ is expected to cause little photodamage to biological samples and is capable of deep tissue penetration, thus such emitters can find application in bio-imaging and bio-sensing. ${ }^{1}$ On the other hand, panchromatic chromophores, with absorption extended toward NIR are eagerly applied in organic photovoltaics. ${ }^{2}$ Most of $\pi$ conjugated systems cover only the visible region of the solar spectrum. Broadening their absorption and shifting it toward longer wavelengths can be efficiently achieved by lowering the energy band gap of the compounds through incorporation of electron-rich and electron-deficient units into the conjugated structure (the push-pull effect). ${ }^{3}$

BODIPY is widely used as electron acceptor for preparation of near infra-red (NIR) fluorophores., ${ }^{4,5}$ The complex exhibits interesting optical properties: fluorescence quantum yield close

${ }^{a} A R C$ Centre of Excellence for Electromaterials Science and the Intelligent Polymer Research Institute, University of Wollongong, NSW 2522, Australia. E-mail: alina. brzeczek@polsl.pl; pawel@uow.edu.au

${ }^{b}$ Faculty of Chemistry, Silesian University of Technology, Marcina Strzody 9 street, 44100 Gliwice, Poland

${ }^{c}$ Wroctaw University of Technology, Wroctaw Center for Networking and Supercomputing, Wybrzeże Wyspiańskiego 27, 50-370 Wroctaw, Poland

$\dagger$ Electronic supplementary information (ESI) available. See DOI: 10.1039/c6ra04984b to 1 , narrow emission and high molar absorption coefficient. ${ }^{6}$ Unmodified BODIPY absorbs and emits light at wavelengths in the visible spectral region $(\sim 500 \mathrm{~nm})$. Through chemical modification, BODIPY absorption and emission can be shifted toward lower energy by (1) appending $\pi$-conjugated groups, at the $\mathrm{C} 1, \mathrm{C} 2$ or $\mathrm{C} 6, \mathrm{C} 7$ positions of pyrrole units, hence extending $\pi$-conjugation of the system; (2) fusing an aromatic ring with the dipyrrane core by an intramolecular oxidative cyclohydrogenation; (3) direct functionalization by introduction of aryl group through double or triple bond into 2,6-positions (4) replacing carbon $\mathrm{C} 8$ with a nitrogen atom (aza-BODIPY dye family) (5) functionalizing at C3, C5 or C8 - positions to obtain aryl-, styryl- or alkynyl-substituted BODIPYs. ${ }^{7}$ BODIPY derivatives have been successfully used as highly emissive materials and efficiently absorbing ones depending upon chemical modification applied. ${ }^{8-13}$ The BODIPY numbering according to IUPAC system is depicted in Fig. 1.

To test the influence of electron - rich substituents on the electronic properties of BODIPY derivatives we have synthesized

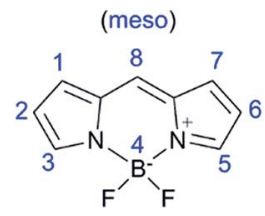

Fig. 1 IUPAC numbering system of the BODIPY core. 
a series of dyes modified at 3,5-positions by vinyl substituents via Knoevenagel condensation. As electron donating moiety, carbazole derivative has been chosen due to its good electron donating and emitting properties. ${ }^{14-16}$ The influence of the length of electron donating linker on the electronic properties of the new compounds was investigated in detail. For elongation of the donor system, thiophene derivatives with different conjugation length have been selected which are known to be an efficient $\pi$-conjugation linker commonly used for this purpose while designing oligomers for conducting polymers. With the help of theoretical calculations, experimental data was used to explain the spectral features of the dyes as well as their electrochemical characteristics. Limits of adopted approach have been elaborated on and discussed.

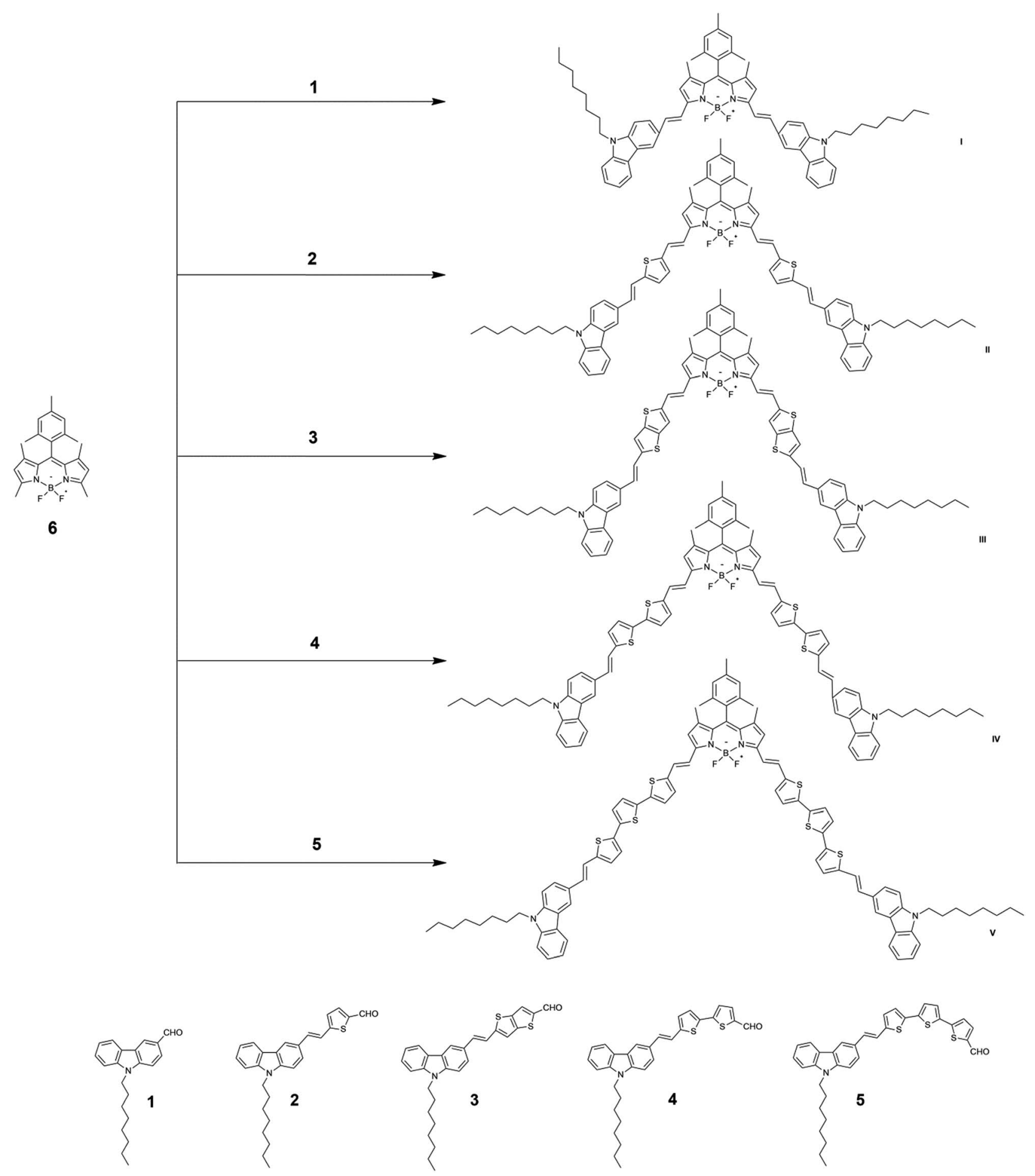

Scheme 1 Generic synthetic route for preparation of dyes I-V. Reagents and conditions: (i) piperidine, $\mathrm{CH}_{3} \mathrm{COOH}, \mathrm{DMF}, \mathrm{MW} 10 \mathrm{~min}, 150{ }^{\circ} \mathrm{C}, 300$ W, 150 psi. 


\section{Synthesis}

BODIPY was synthesized by the acid-catalysed condensation of mesitaldehyde with 2,4-dimethylpyrrole affording dipyrromethane, which was oxidized with DDQ to dipyrrane followed by complexation with boron trifluoride etherate. ${ }^{17}$ The aldehyde 1 was prepared by standard Vilsmeier-Haack formylation reaction using DMF and phosphorous oxychloride. The synthesis of subsequent aldehydes, with systematically extended conjugation length, was conducted via Wittig reaction between [(9-octyl-9H-carbazol-3-yl)methyl]triphenyl-phosphonium bromide and $\alpha, \alpha^{\prime}$-dicarbaldehyde derivatives. The products of the reactions were mixtures of $E$ and $Z$ isomers, obtained in the ratio of $3: 1$ respectively. Treatment with trifluoroacetic acid (TFA) isomerized the mixtures into pure $E$ products. The synthetic route toward aldehydes $\mathbf{2 - 5}$ is summarized in ESI (Scheme SI.1†). The series of BODIPY dyes have been synthesized via microwave assisted Knoevenagel condensation of tetramethyl derivative 6 with aldehydes 1-5 (Scheme 1). The reaction times were shortened compared to conventional thermal processes, ${ }^{\mathbf{1 4}}$ however, obtained yields were low to moderate (30-40\%). Due to their highest acidity, methyl groups at C3 and C5 positions were almost exclusively involved in the condensation reaction ${ }^{18}$ affording disubstituted products with some amount of mono derivatives. ${ }^{1} \mathrm{H},{ }^{13} \mathrm{C}$ NMR spectra are available in ESI (Fig. SI.1 and SI.2†).

\section{Photophysical properties}

Bathochromic shift of both absorption and emission spectra was observed for aldehydes 1-5 with elongation of their conjugated system (Fig. 2). The effect involved displacement of absorption maxima from $294 \mathrm{~nm}$ for 1 to $453 \mathrm{~nm}$ for 5 . The emission maxima followed the same trend, shifting from 410 $\mathrm{nm}$ for 1 to $600 \mathrm{~nm}$ for $\mathbf{5}$. Likewise, extinction coefficient of the lowest energy band also increased in magnitude being lowest for $\mathbf{2}$ and highest for $\mathbf{5}$.

Absorption and emission spectra of disubstituted-BODIPY dyes I-V are presented in Fig. 3 and their photophysical properties are summarized in Table 1.

Dye I displays intense absorption bands in the 300-450 and $600-720 \mathrm{~nm}$ ranges. The peak at $672 \mathrm{~nm}$ corresponds to $\pi-\pi^{*}$ transition with slight charge transfer character. HOMO is delocalized on $\pi$-orbitals of BODIPY and carbazole while LUMO is delocalized on $\pi$-orbitals of BODIPY. The transition at $428 \mathrm{~nm}$ corresponds to HOMO-1 to LUMO transition from carbazole to BODIPY, where these transitions possess stronger charge transfer character. The highest energy transition at $332 \mathrm{~nm}$ is the HOMO to LUMO+1 transition, where LUMO+1 is delocalized nearly on the whole $\pi$-conjugated system. Detailed description of individual transitions and their relationships with spatial distributions of respective molecular orbitals will be given below. The diagrams of all molecular orbitals are included in Fig. SI.4. $\dagger$

Introduction of thiophene rings between vinyl-BODIPY and carbazole moieties pushes the absorption maxima edge toward red from $680 \mathrm{~nm}$ for dye I to $750 \mathrm{~nm}$ for dye II. Introduction of additional thiophene rings in compounds III-V, does not bring about further bathochromic shift, but rather a systematic increase in absorption coefficient for the higher energy transitions located between 2.5 and $4 \mathrm{eV}$. This effect is clearly seen when spectra of all five dyes are normalised to a common maximum of the least energetic absorption band (Fig. 4). Dye I high energy transitions start only above $2.5 \mathrm{eV}$ and their intensity is well below that of the $1.85 \mathrm{eV}$ peak. Introduction of single thiophene spacer affording dye II, brings profound changes in that respect. Firstly, the aforementioned redshift of the lowest energy band takes place. Secondly, bands at ca. 2.5 and $3 \mathrm{eV}$ receive substantial boost making them levelled with
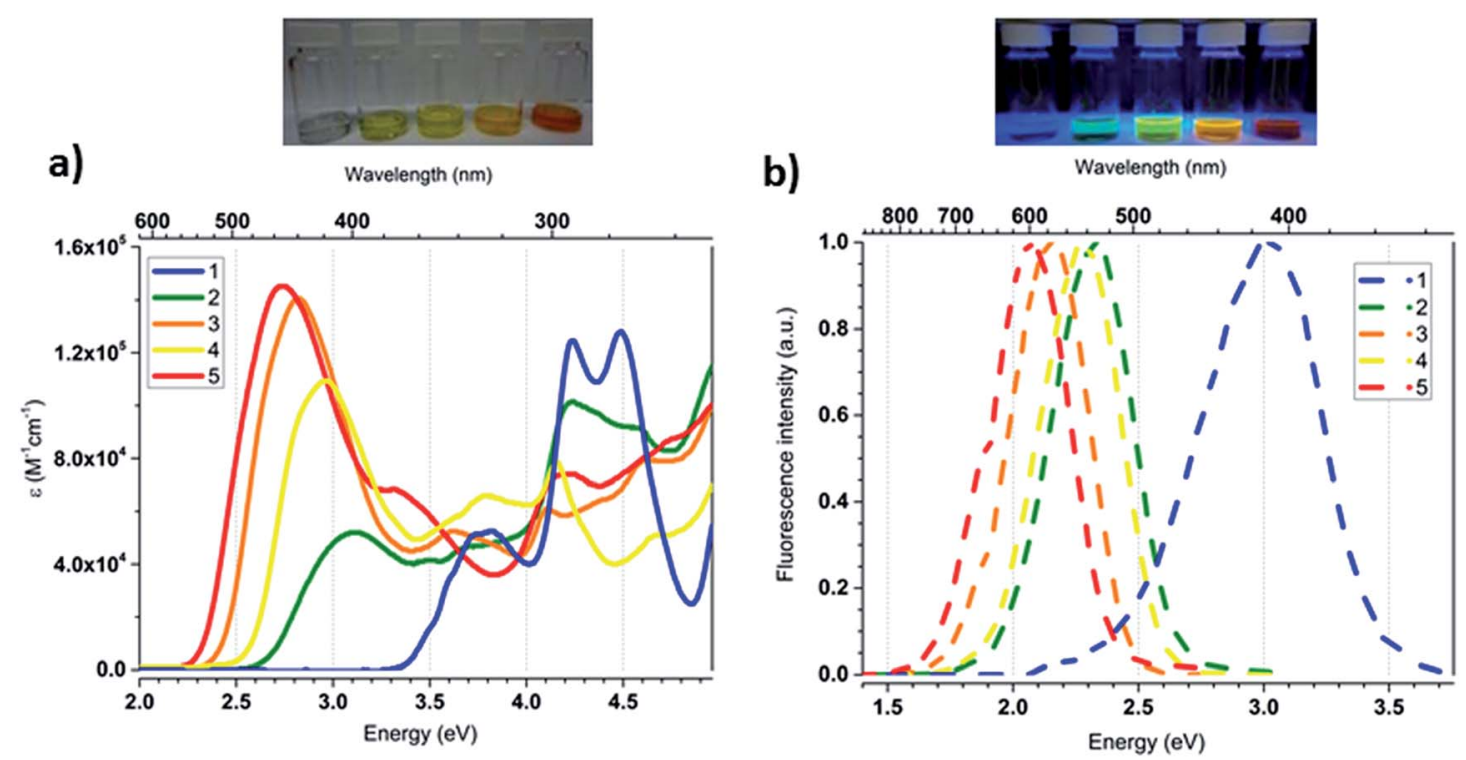

Fig. 2 (a) Absorption spectra of aldehydes 1-5 measured in $\mathrm{CH}_{2} \mathrm{Cl}_{2}$ together with colors of their solutions. (b) Emission spectra of aldehydes $1-5$ in $\mathrm{CH}_{2} \mathrm{Cl}_{2}$ and their emitted colors upon UV illumination. 


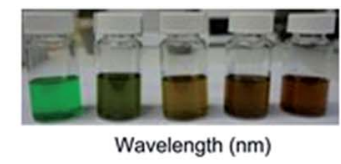

a)

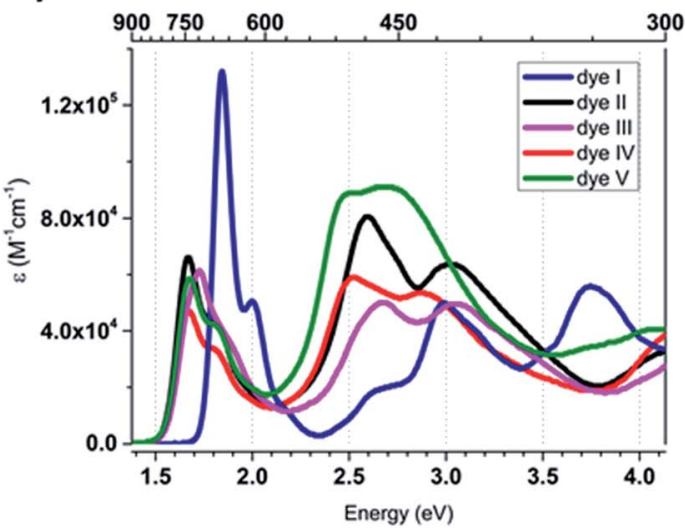

b)

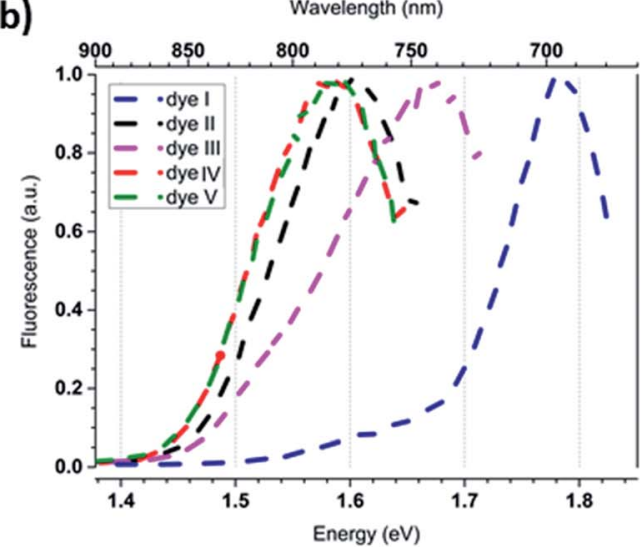

Fig. 3 Absorption (a) and emission (b) spectra of disubstituted BODIPY derivatives I-V in $\mathrm{CH}_{2} \mathrm{Cl}_{2}$.

Table 1 Photophysical data for $\mathrm{I}-\mathrm{V}$ in $\mathrm{CH}_{2} \mathrm{Cl}_{2}$ at room temperature

\begin{tabular}{|c|c|c|c|c|c|c|c|c|}
\hline Compound & $\lambda_{\mathrm{abs}}{ }^{a}[\mathrm{~nm}]$ & $\varepsilon\left(\mathrm{M}^{-1} \mathrm{~cm}^{-1}\right) \times 10^{3}$ & $\lambda_{\mathrm{em}}[\mathrm{nm}]$ & Stokes shift $\left[\mathrm{cm}^{-1}\right]$ & $\varphi_{\mathrm{F}}^{b}[\%]$ & $\tau_{\mathrm{F}}[\mathrm{ns}]$ & $k_{\tau}\left[10^{8} \mathrm{~s}^{-1}\right]$ & $k_{\mathrm{nr}}\left[10^{8} \mathrm{~s}^{-1}\right]$ \\
\hline I & 672 & 132 & 698 & 554 & 34 & 3.8 & 0.894 & 1.736 \\
\hline II & 740 & 80.5 & 775 & 611 & 2 & 3.3 & 0.006 & 0.267 \\
\hline III & 718 & 61 & 741 & 433 & $<1$ & 3.1 & $<0.003$ & $<0.322$ \\
\hline $\mathbf{V}$ & 736 & 91 & 780 & 767 & $<1$ & 3.0 & $<0.003$ & $<0.333$ \\
\hline
\end{tabular}

${ }^{a}$ Lowest-energy absorption maximum. ${ }^{b}$ Absolute fluorescence quantum yields measured using an integrating sphere.

the one at $1.68 \mathrm{eV}$, and thirdly the absorption peak widths broaden, making the low and high energy transitions overlap to yield coverage of the green to orange part of the visible spectrum, affording the dye its panchromatic character. Introducing subsequent thiophene units sees further red-shift broadening of the high energy bands ensemble complemented by their intensification, making them the most prominent absorption features for dyes IV and V. This spectral overhaul can be traced to evolution of oligothiophene spectra, whose transition energies are tuned by push-pull BODIPY and carbazole auxochromes. Dye III stands out here, particularly when set against dye IV, where both share a double thiophene motif. While

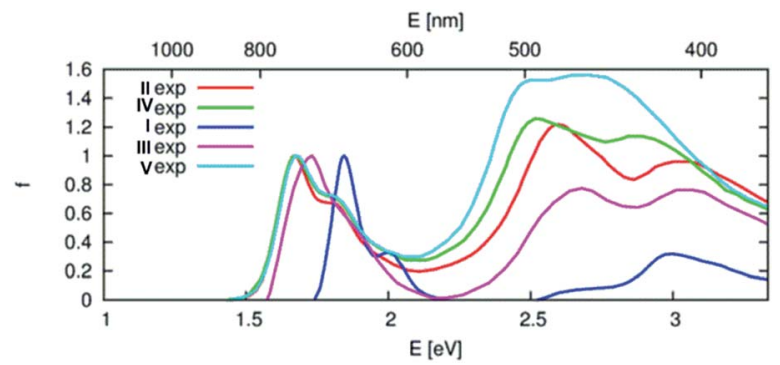

Fig. 4 Spectra of dyes I through $V$ normalised to the lowest energy absorption band. sharing similar absorption profile pattern with IV, its energies are less red-shifted and the high energy transitions set considerably less intense, even compared with the mono-thiophene derivative I. It thus appears that fused thiophene conjugation pattern affords less efficient energy absorption cross section when compared to $\alpha-\alpha^{\prime}$ bond coupled thiophene motif. One reason for this could be molecular nimbleness of individual thiophene rings, easily rocking along this $\alpha-\alpha^{\prime}$ bond scaffold, while the other could be their distributed aromatic character, compared with that of the condensed, ten $\pi$-electron thienothiophene assembly.

Similarly to absorption spectra, the red shift of emission spectra from $700 \mathrm{~nm}$ for dye I to $780 \mathrm{~nm}$ for dye II is observed, but further elongation of $\pi$ system from II to $\mathbf{V}$ fails to deliver additional bathochromic progression. However, in clear contrast to the previous report, ${ }^{15}$ a dramatic drop in quantum yield from $34 \%$ for I to $<\mathbf{1 \%}$ for II, III, IV and V is observed. With increasing contribution of thiophene units, it is commonly observed that fluorescence quantum yields tend to decrease. ${ }^{\mathbf{1 9 , 2 0}}$ In our series, however, fluorescence quenching is not caused by introduction of thiophene units, since the quantum yield drop is already observed when carbazole units are appended to BODIPY system (QY of BODIPY system (6) - 90\%, BODIPY substituted by two carbazoles at C3, C5 positions (I) - 34\%). This is presumably the effect of increase of the push-pull effect in 


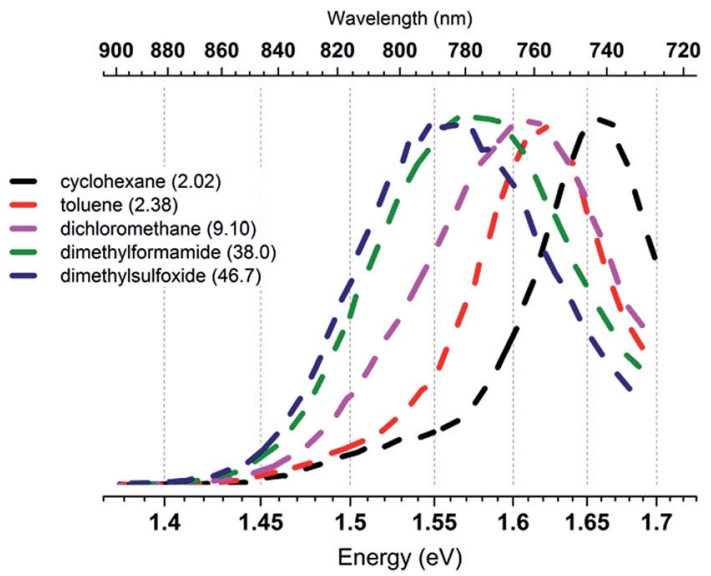

Fig. 5 Normalized fluorescence spectra of dye II in solvents of various polarities. Dielectric constants of the solvents are indicated in the agenda.

the molecule, lower energy band gap for derivatives II, III, IV, $\mathbf{V}$ and resulting electron exchange by means of the Dexter mechanism. $^{20,21}$ To better understand this, fluorescence lifetimes $(\tau)$ of the derivatives were measured. For dyes with elongated $\pi$ system, a significant decrease of radiative decay rate $\left(k_{\tau}\right)$ is observed as compared to dye I. Simultaneously the ratio of nonradiative decay rates $\left(k_{\mathrm{nr}}\right)$ to $\left(k_{\tau}\right)$ are much higher than for dye I, substantiating the observed significant drop in QY. Lower energy gaps of dyes II, III, IV and $\mathbf{V}$ can enhance internal conversion, which is one pathway for nonradiative relaxation of a photoinduced excited state. ${ }^{22}$

Small increase in Stokes shifts is observed from $26 \mathrm{~nm}$ for I to $44 \mathrm{~nm}$ for $\mathbf{V}$ which can be attributed to geometry relaxation upon photoexcitation and its substantial effect on the energy levels of molecular orbitals as proposed by Y. Chen et al. ${ }^{23}$ The character of the lower energy transition at $1.5-2 \mathrm{eV}$ was investigated by examining the influence of solvent polarity on fluorescence spectra (example results for II are shown in Fig. 5 and are summarized in Table 2). Upon changing the solvent polarity from cyclohexane to DMSO, the emission bands broaden and red shift of the emission maxima is observed (solvatochromic effect). This suggests that the transition corresponds to intramolecular CT, where dyes have a more polar electronic structure than in the ground state.

\section{Quantum calculations}

Theoretical absorption spectra are in a good agreement with the experimental results (Fig. 6). The first low energy transition for all studied structures is related to transition from HOMO to LUMO. For all structures HOMO is strongly delocalized on the $\pi$

Table 2 Emission maxima for dye II in solvents of different polarity

\begin{tabular}{llllll}
\hline Solvent & DMSO & DMF & $\mathrm{CH}_{2} \mathrm{Cl}_{2}$ & Toluene & Cyclohexane \\
\hline$\lambda_{\max }[\mathrm{nm}]$ & 800 & 790 & 770 & 765 & 747
\end{tabular}
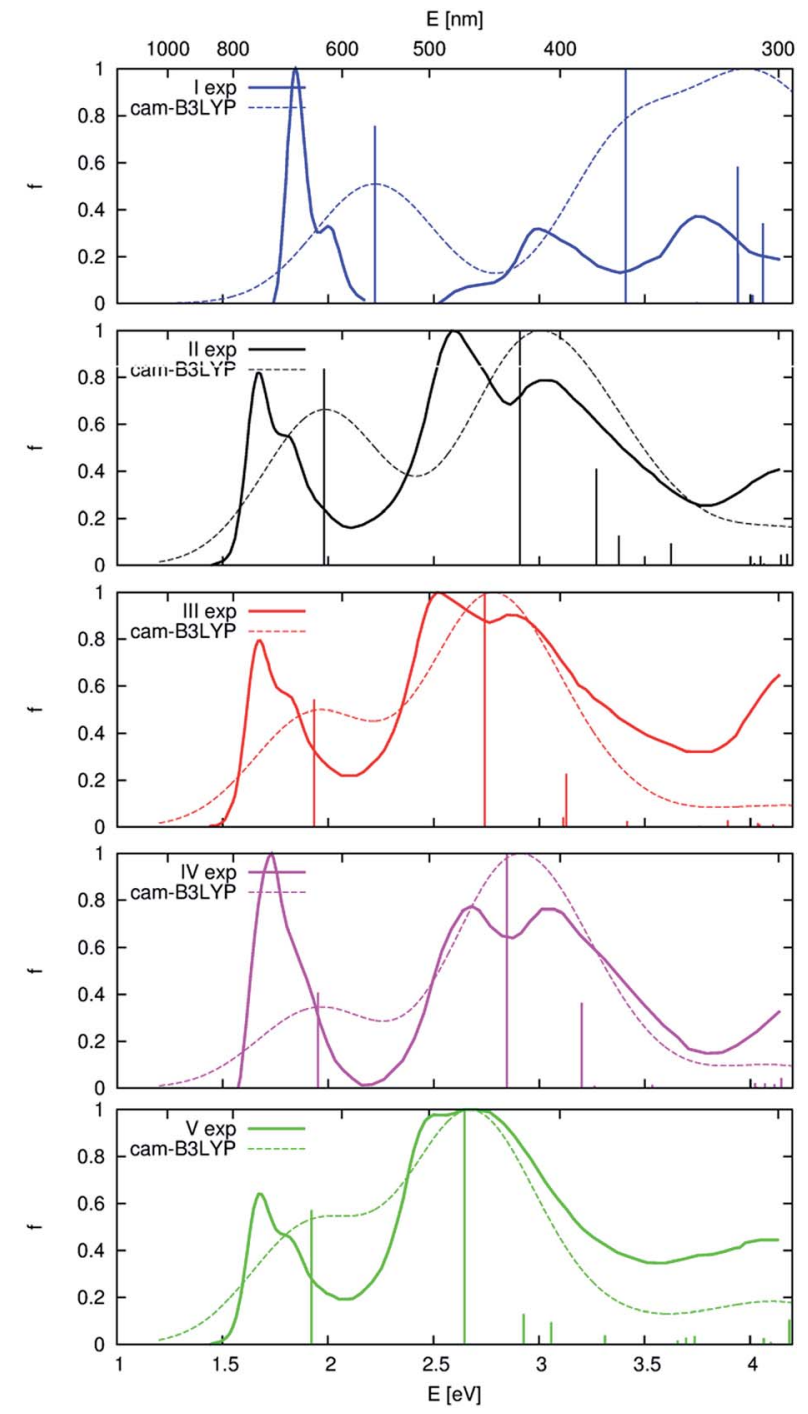

Fig. 6 Comparison of theoretical and experimental absorption spectra for studied compounds. Dashed lines for theoretical spectra were calculated as a sum of the Gaussian curves with arbitrary width at half maximum. All spectra were normalized to 1 for most intensive transition.

orbitals of the donor part of the molecule, except terminal part of the carbazole for II-V (Fig. 7).

LUMO is localized mostly on the BODIPY part of the molecule. Delocalization of HOMO on longer $\pi$-conjugated thiophene linkers results in increase of charge transfer character of the HOMO to LUMO transition. Introduction of thiophene based linker between carbazole and BODIPY decreases the contribution of carbazole unit to HOMO orbital. That can explain why low energy transition of all structures but $\mathbf{I}$ are so similar. For longer $\pi$-conjugated thienyl linkers, frontier orbitals are localized mostly at them and BODIPY with only small electron density conferred to carbazole fragments.

Theoretical excitation energy for structure $\mathrm{I}$ is $3.4 \mathrm{eV}$ and it red-shifts with extension of $\pi$-conjugation of the linker. This excitation is related with transition from HOMO-1 to LUMO. This transition has even more charge transfer character because 


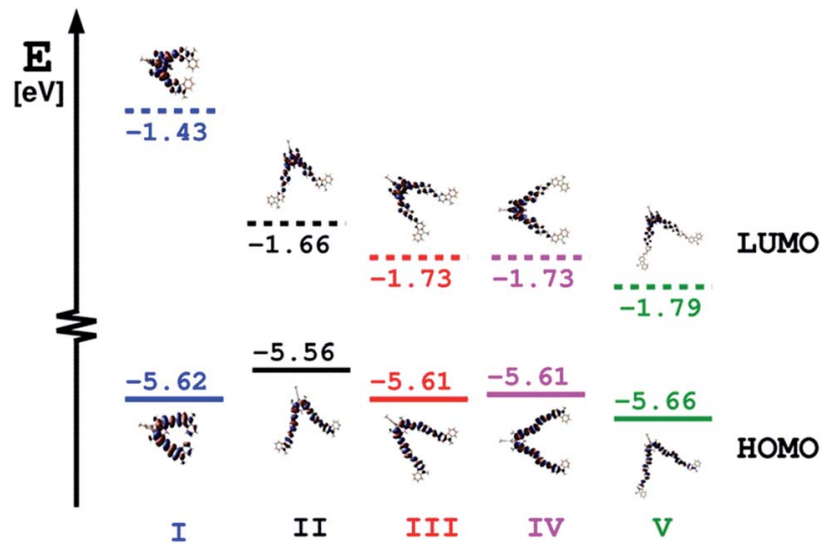

Fig. 7 Distribution of frontier orbitals of dyes I-V calculated using the CAM-B3LYP 6-31G(d)(p) DFT method with HOMO and LUMO energy levels. In order to accelerate the convergence of optimizations the long octyl chains were replaced with methyl groups.

HOMO-1 is delocalized on thiophene linkers and carbazole unit. The low energy transition for all structures with linker has similar excitation energy just below $2 \mathrm{eV}$, but next transition sifts from $2.9 \mathrm{eV}$ for structure II to $2.6 \mathrm{eV}$ for structure $\mathrm{V}$. Next excitation is related to transition from HOMO to LUMO+1. For structures with linker, LUMO+1 is delocalized mostly on the linkers between BODIPY and carbazole. The shapes of all frontier orbitals of considered structures are presented in ESI Fig. SI.4. $\dagger$

\section{Electrochemical properties}

Electrochemical investigations of compounds I through $\mathbf{V}$ were carried out using cyclic voltammetry (CV) offering insight to the accessibility and distribution of redox states, expressed quantitatively by parameters such as ionization potential (IP) and electron affinity (EA). ${ }^{24}$ Both parameters can be computed from CV data, where IP is obtained from the onset potential of the anodic peak corresponding to oxidation of the neutral compound to a radical cation, while EA can be obtained from the onset potential of the cathodic peak corresponding to reduction of the neutral compound to a radical anion. IP and EA can be associated with HOMO and LUMO levels whose difference in energy gives the energy gap between frontier molecular orbitals of a molecule. ${ }^{25,26}$

As reported in, ${ }^{27,28}$ unsubstituted BODIPY features a reversible redox couple at $-1.15 \mathrm{~V}$ and an irreversible oxidation peak at $+1.17 \mathrm{~V}$. Our investigated dyes undergo oxidation as well as reduction processes as seen in their cyclic voltammograms presented in Fig. 8. Cathodic redox pairs of all dyes feature similar reversible (albeit not in electrochemical sense Table SI.1†) single electron characteristics, while the shape of CV curves corresponding to generation of successive cationic species is individual for each dye.

Dye I (Fig. 8, blue line) demonstrates two reversible redox couples at $+0.22 \mathrm{~V}$ and $+0.47 \mathrm{~V}$, consistent with the literature data for a similar compound with different substituents at BODIPY's meso position and at carbazole's nitrogen atom. ${ }^{29}$
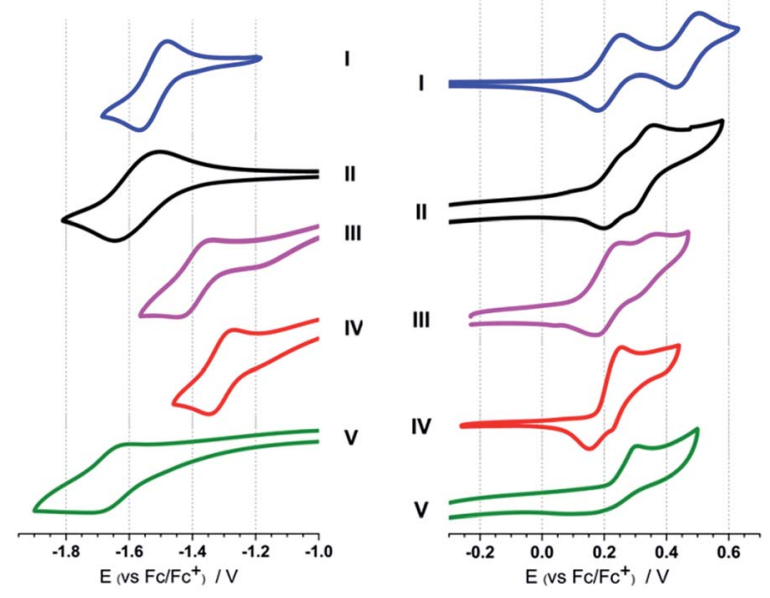

Fig. 8 Cyclic voltammograms of compounds I, II, III, IV and V registered in $0.1 \mathrm{M} \mathrm{Bu}_{4} \mathrm{NPF}_{6}$ in dichloromethane at $50 \mathrm{mV} \mathrm{s}^{-1}$.

Both anodic peaks are reversible (Table SI.1†), implying that radical cation and dication of $\mathbf{I}$ are sufficiently long-lived not to undergo dimerization at the time scale of voltammetric experiment. This observation is supported by DFT computations whereby the electron density of SOMO orbital is delocalised over the whole molecule, diluting unpaired electron density at the 3positions of carbazole where dimerization would be expected (Fig. SI.4†). This property is also observed for compound II (Fig. 8, black line), whose CV curve shows two successive oxidation steps. The two redox pairs at $c a .+0.23 \mathrm{~V}$ and $c a .+0.32$ $\mathrm{V}$ appear reversible but their overlap indicates that the two redox steps closely follow one another.

During anodic cycle of III (Fig. 8, magenta line) two, even more closely overlapping semi-reversible redox pairs are observed at $c a .+0.21 \mathrm{~V}$ and $c a .+0.33 \mathrm{~V}$. Amalgamation of redox steps observed in II and III comes from extension of conjugation of the $\pi$-bond system afforded by introduction of thiophene groups stabilizing positively charged states of these molecules. In the case of IV (Fig. 8, red line), a single CV oxidation peak at $+0.25 \mathrm{~V}$ is discernible, suggesting concurrent oxidation to doubly charged species followed by double step reduction of these oxidized species in the reverse cathodic sweep. Finally $\mathbf{V}$ (Fig. 8 green line) demonstrates single oxidation peak at $+0.23 \mathrm{~V}$ followed by continuous and diffused current wave. In the reverse sweep, an extended reduction feature develops, peaking at $+0.09 \mathrm{~V}$, reminiscent of broad reduction peaks of long oligothiophenes or polythiophene. ${ }^{28}$ This demonstrates unperturbed delocalization of positive charge carriers across the BODIPY-oligothiophene arms scaffold restricted only by breadth of molecular orbitals of positively charged species in this dye. No signs of oxidative dimerization are observed on account of this extensive delocalisation of the unpaired electron as portrayed by the contours of SOMO orbitals of radical cations of investigated molecules (see Fig. SI. $4 \dagger$ ).

DFT computations of LUMO frontier molecular orbitals indicate that reduction of dyes $\mathbf{I}$ through $\mathbf{V}$ should proceed 
predominantly at the BODIPY moiety. Taking into account that our BODIPY pendants demonstrate electron donating properties, it is expected that they modulate the energy of this first unoccupied energy level by way of both mesomeric and inductive factors. With this in mind, the reduction potential of dyes $\mathbf{I}$ through $\mathrm{V}$ should deviate from the value of $-1.15 \mathrm{~V}$ for unsubstituted BODIPY core $^{\mathbf{3 0 , 3 1}}$ depending on the inductive effects of the carbazole and thiophene motifs as well as on the effective contribution of their non-bonding electron states to BODIPY's LUMO level. ${ }^{21}$ It was previously reported that shift of redox potentials reflects the varying degrees to which the donor couples to the extended BODIPY unit. ${ }^{32}$ Likewise observation is made in this study, with all pendants moving the reduction potentials to more negative values, albeit to a varying extent. Taking onset potentials as the best representative measures of individual redox steps, EA and IP values have been computed from CV data, and the results are gathered in Table $3 .^{21,29,33}$

At first sight, there appears to be little correlation of both IP and EA values with chemical structure of investigated BODIPY substituents, especially the length of thiophene linkers. Except for dye III, introduction of thienyl spacers between BODIPY core and carbazole terminators slightly increases the oxidation potential of the resulting dyes compared to dye I. Trends emerge when spatial distributions of HOMO and LUMO orbitals in these molecules are quantified. Computing a conjugation ratio, expressed as the number of atoms contributing their atomic orbitals to a given molecular orbital to the total number of atoms in a molecule (Table SI. $2 \dagger$ ), a clear, negatively sloped linear correlation with both EA and IP values is established for all five dyes. With increasing HOMO conjugation ratio, IP values were found to decrease. Such relationship suggests that appending BODIPY with electron-abundant units at the 3,5 positions need not necessarily translate to effective enhancement of ionization propensity. Extending conjugation is only effective if the spatial breadth of the HOMO orbital follows suit. This is particularly evident when all five dyes are compared one against another. Dye $\mathbf{V}$ with terthiophene linker would be expected to oxidize most easily, which turns out exactly opposite with $\mathbf{V}$ having the highest IP value. Thienothiophene containing dye III demonstrates the lowest IP value of the set, which could be linked to its fused and rigid double thiophene motif. Similarly, dye I having second to lowest IP value, features stiff carbazole ring attached to a vinyl linker, which aids

Table 3 Electrochemically determined values of IP and EA from the redox potentials of dyes I through $\mathrm{V}$

\begin{tabular}{lllllll}
\hline Dye & $E_{\text {onset }}^{\text {ox }}[\mathrm{V}]$ & $E_{\text {onset }}^{\mathrm{red}}[\mathrm{V}]$ & $\mathrm{IP}^{a}[\mathrm{eV}]$ & $\mathrm{EA}^{b}[\mathrm{eV}]$ & $E_{\mathrm{g}}^{\mathrm{cv}}$ & $E_{\mathrm{g}}^{\mathrm{opt}}$ \\
\hline BODIPY $^{4,5}$ & +1.17 & -1.15 & - & - & - & - \\
I & +0.14 & -1.45 & 5.24 & 3.65 & 1.59 & 1.75 \\
II & +0.18 & -1.43 & 5.28 & 3.67 & 1.61 & 1.53 \\
III & +0.12 & -1.34 & 5.22 & 3.76 & 1.46 & 1.54 \\
IV & +0.17 & -1.26 & 5.27 & 3.84 & 1.43 & 1.53 \\
V & +0.22 & -1.57 & 5.32 & 3.53 & 1.79 & 1.54 \\
\multicolumn{7}{l}{ Calculated using equation: IP $=|e| \cdot\left(E_{\text {onset }}^{\text {ox }}+5.1\right)}$. \\
equation: EA $=|e| \cdot\left(E_{\text {onset }}^{\text {red }}+5.1\right)$.
\end{tabular}

delocalization of the HOMO orbital over such planar scaffold. Dyes II, IV and $\mathbf{V}$ on the other hand all feature $\alpha, \alpha^{\prime}$ coupled thiophene rings which are known to experience a torsional twist one relative to another. Such twist disrupts effective $\pi$-conjugation lowering the HOMO level energy and translating to increase in IP value of the molecule.

Impact on EA values was found to be more pronounced, with thienyl-carbazole pendants lowering the reduction potential of BODIPY core by at least $0.1 \mathrm{eV}$. Changing the thienyl content made further decreases of reduction potentials by as much as $0.3 \mathrm{eV}$ between dye IV and V. Just like for the relation of IP with HOMO conjugation ratio, again, EA estimated from the reduction potential, is found decreasing with increasing LUMO conjugation ratio. All dyes share the same electron-withdrawing BODIPY and electron-donating carbazole groups, so variations of reduction potential reflect the impact of thienyl units on the energy of antibonding states and their ability to accommodate a surplus electron charge. Bigger EA values indicate greater stability of the radical anion of a reduced molecule, hence the observed trend could be taken as manifestation of relatively mild electron donating power of the thiophene moieties which destabilize the LUMO orbital upon increased contribution of their atomic orbitals to it. Individual contributions appear unsystematic however, with bis(thiophene) groups (dyes III and IV) catering the LUMO orbital least, followed by monothiophene (dye II) and terthiophene (dye V) contributing most to expansion of delocalization of this molecular orbital. Considering clear decrease of carbazole group's contribution to the LUMO orbital upon its increased separation from the BODIPY core, all this suggests that mesomeric factors, favouring localization, take clear precedence over inductive ones as far as propensity for electron uptake of investigated molecules is concerned.

Electrochemically determined individual values of energies of electron abstraction and incorporation permit computation of energy gap estimates, which can be related to differences in frontier molecular orbital energies if solvation energies of radical cation and anion cancel each other out. ${ }^{34}$ To a first approximation, this can often be taken as being the case, permitting comparison of electrochemical energy gaps with optical ones determined from UV-Vis spectra. Table 3 gathers these results for dyes I through $\mathbf{V}$. UV-Vis spectra report little if no change of Eg values for thienyl bearing dyes II through $\mathbf{V}$, and electrochemical results for II, III and IV closely follow suit with differences of $\leq 0.1 \mathrm{eV}$ accountable for the experimental error. Greater differences are observed for I and V. Here, one should consider that solution UV-Vis spectra deliver information about electron transitions of an isolated solvated molecule free to reorient its conformation upon electron transition act. In the case of electrochemistry, redox steps proceed for electrode surface entangled molecule, whose conformation will differ from a relaxed solvated shell one. This will determine the height of the heterogeneous electron transfer electron barrier, as well as influence the vibronic states the molecule can be delivered to at the end of electron transfer act. 


\section{Experimental}

\section{Methods}

NMR spectra were recorded at $400 \mathrm{MHz}$ for ${ }^{1} \mathrm{H}$ NMR and 101 $\mathrm{MHz}$ for ${ }^{13} \mathrm{C}$ NMR on a Bruker $400 \mathrm{MHz}$ spectrometer; $\delta$ values are in parts per million (ppm) relative to tetramethylsilane (TMS) internal standard. MALDI-TOF spectra were recorded on Shimadzu AXIMA Performance instrument with 1,8,9-anthracenetriol as supporting matrix. Electrochemical measurements were carried out on $\mathrm{CHI}$ 650c electrochemical workstation $(\mathrm{CH}$ Instruments Inc.). Dichloromethane (DCM) containing $0.1 \mathrm{M}$ tetrabutylammonium hexafluorophospate $\left(\mathrm{Bu}_{4} \mathrm{NPF}_{6}\right.$; Sigma Aldrich 98\%) was used as the electrolyte medium. A standard three-electrode system was used: a platinum wire as a working electrode, a platinum spiral as an auxiliary electrode and a silver wire as a pseudo-reference electrode, whose exact potential was calibrated versus ferrocene/ferrocinium redox couple. Cyclic voltammetry measurements were performed in $1 \mathrm{mM}$ solution of the analyte. Working solutions were purged with argon prior to measurements.

The structures of dyes were optimized with use of B3LYP functional and 6-31G(d)(p) basis set. The aliphatic chains were neglected and substituted by methyl groups during theoretical calculations. For optimized structures theoretical spectra were calculated in terms of time depended density functional theory (TDDFT) with use of CAM-B3LYP functional and 6-31G(d)(p) basis set. All calculations were carried out with use of GAUSSIAN 09 package. The shapes of molecular orbitals were printed using MOLDEN software.

\section{Materials}

Carbazole, thiophene-2,5-dicarbaldehyde, thieno[3,2- $b]$ thiophene2,5-dicarbaldehyde and other required materials were purchased from Sigma Aldrich and used as received. 2,2'-Bithiophene-5, $5^{\prime}$ dicarbaldehyde and 2,2':5'2 $2^{\prime \prime}$-terthiophene-5,5'-dicarbaldehyde were synthesized according to the described procedures. ${ }^{35,36}$ Column chromatography was performed using silica gel 60 (0.040-0.063 mm) purchased from Merck.

9-Octyl-3-carbazolecarboxaldehyde (1). $\mathrm{POCl}_{3}(2.5 \mathrm{~mL}, 27$ $\mathrm{mmol}$ ) was added dropwise into $35 \mathrm{~mL}$ of DMF at $0{ }^{\circ} \mathrm{C}$. Carbazole $(7 \mathrm{~g}, 25 \mathrm{mmol})$ was added in portions and the temperature was slowly increased to $80{ }^{\circ} \mathrm{C}$. The mixture was stirred for $6 \mathrm{~h}$ after which, it was cooled down and poured into water $(150 \mathrm{~mL})$, extracted with $\mathrm{CH}_{2} \mathrm{Cl}_{2}(4 \times 30 \mathrm{~mL})$ and dried over anhydrous $\mathrm{MgSO}_{4}$. The solvent was removed under diminished pressure and the residue was purified by silica gel packed column chromatography (hexane : $\mathrm{CH}_{2} \mathrm{Cl}_{2} 2: 1, \mathrm{v} / \mathrm{v}$ ) to afford pale yellow solid (5 g, yield: $65 \%$ ).

${ }^{1} \mathrm{H}$ NMR (400 MHz, $\left.\mathrm{CDCl}_{3}\right) \delta 10.07(\mathrm{~s}, 1 \mathrm{H}), 8.56(\mathrm{~d}, J=1.6 \mathrm{~Hz}$, $1 \mathrm{H}), 8.12(\mathrm{~d}, J=7.6 \mathrm{~Hz}, 1 \mathrm{H}), 7.97(\mathrm{dd}, J=8.4,1.6 \mathrm{~Hz}, 1 \mathrm{H}), 7.51$ (ddd, $J=8.4,7.6,1.2 \mathrm{~Hz}, 1 \mathrm{H}), 7.43$ (d, $J=1.2 \mathrm{~Hz}, 1 \mathrm{H}), 7.41$ (s, $1 \mathrm{H}), 7.36-7.26(\mathrm{~m}, 1 \mathrm{H}), 4.27(\mathrm{t}, J=7.2 \mathrm{~Hz}, 2 \mathrm{H}), 2.04-1.77(\mathrm{~m}$, $2 \mathrm{H}), 1.48-1.13(\mathrm{~m}, 10 \mathrm{H}), 0.85(\mathrm{t}, J=6.9 \mathrm{~Hz}, 3 \mathrm{H}) .{ }^{13} \mathrm{C}$ NMR $(101$ $\left.\mathrm{MHz}, \mathrm{CDCl}_{3}\right) \delta 191.70,144.07,141.18,128.53,127.12,126.70$, 123.93, 123.07, 123.01, 120.72, 120.28, 109.40, 108.92, 43.41, $31.75,29.31,29.13,28.91,27.25,22.59,14.05$.

\section{General procedure for the preparation of aldehydes 2-5}

Phosphonium [(9-octyl-9H-carbazol-3-yl)methyl]triphenyl bromide $(0.80 \mathrm{~g}, 1.2 \mathrm{mmol})$ and corresponding dialdehyde $(1.2 \mathrm{mmol})$ were dissolved in anhydrous $\mathrm{CH}_{2} \mathrm{Cl}_{2}(50 \mathrm{~mL}) . \mathrm{K}_{2} \mathrm{CO}_{3}(0.34 \mathrm{~g}, 2.4 \mathrm{mmol})$ and 18-Crown-6 (0.05 g) were added and mixture was refluxed for $1.5 \mathrm{~h}$. The solid phase was filtered off and the solvent was evaporated. The residue was purified by silica gel column chromatography using $\mathrm{CH}_{2} \mathrm{Cl}_{2}$ as the eluent to afford the mixture of $E$ and $Z$ isomers ( $3: 1$ ratio). The mixture of $E$ and $Z$ isomers was dissolved in $\mathrm{DCM} / \mathrm{H}_{2} \mathrm{O} / \mathrm{TFA} 9 \mathrm{~mL}: 3 \mathrm{~mL}: 9 \mathrm{~mL}$ and stirred for $30 \mathrm{~min}$. Phases were separated, organic one was neutralized with $\mathrm{NH}_{3}$, dried over $\mathrm{MgSO}_{4}$ and evaporated to dryness. The residue was purified by silica gel packed column chromatography (silica gel, DCM) to give $E$ isomer.

(E)-5-(2-(9-Octyl-9H-carbazol-3-yl)vinyl)thiophene-2-carbaldehyde (2). Yellow solid, $0.31 \mathrm{~g}$ yield $62 \% ;{ }^{1} \mathrm{H}$ NMR (400 $\mathrm{MHz}, \mathrm{CDCl}_{3}$ ) $\delta 9.85(\mathrm{~s}, 1 \mathrm{H}), 8.23(\mathrm{~d}, J=1.6 \mathrm{~Hz}, 1 \mathrm{H}), 8.12(\mathrm{~d}, J=7.6 \mathrm{~Hz}, 1 \mathrm{H})$, 7.67 (d, $J=3.6 \mathrm{~Hz}, 1 \mathrm{H}), 7.64$ (dd, $J=8.4,1.6 \mathrm{~Hz}, 1 \mathrm{H}), 7.51-7.46$ $(\mathrm{m}, 1 \mathrm{H}), 7.40(\mathrm{~d}, J=16.0 \mathrm{~Hz}, 1 \mathrm{H}), 7.38(\mathrm{~d}, J=16.0 \mathrm{~Hz}, 1 \mathrm{H}), 7.29-$ $7.22(\mathrm{~m}, 3 \mathrm{H}), 7.15(\mathrm{~d}, J=3.6 \mathrm{~Hz}, 1 \mathrm{H}), 4.30(\mathrm{t}, J=7.2 \mathrm{~Hz}, 2 \mathrm{H})$, 1.97-1.78 (m, 2H), 1.44-1.11 (m, 10H), $0.86(\mathrm{t}, J=6.9 \mathrm{~Hz}, 3 \mathrm{H})$. ${ }^{13} \mathrm{C} \mathrm{NMR}\left(101 \mathrm{MHz}, \mathrm{CDCl}_{3}\right) \delta 182.43,153.71,140.95,140.92$, 140.76 , 137.42, 134.35, 126.97, 126.12, 125.53, 124.76, 123.37, $122.77,120.48,119.49,119.37,118.03,109.12$, 109.04, 43.29, 31.77, 29.34, 29.15, 28.99, 27.29, 22.58, 14.03.

(E)-5-(2-(9-Octyl-9H-carbazol-3-yl)vinyl)thieno[3,2-b]thiophene2-carbaldehyde (3). Yellow solid, $0.45 \mathrm{~g}$, yield 79\%; ${ }^{1} \mathrm{H}$ NMR (400 $\left.\mathrm{MHz} \mathrm{CDCl}_{3}\right) \delta 9.93(\mathrm{~s}, 1 \mathrm{H}), 8.22(\mathrm{~d}, J=1.6 \mathrm{~Hz}, 1 \mathrm{H}), 8.12(\mathrm{~d}, J=7.6$ $\mathrm{Hz}, 1 \mathrm{H}), 7.87$ (s, 1H), 7.65 (dd, $J=8.4,1.2 \mathrm{~Hz}, 1 \mathrm{H}), 7.51-7.47$ (m, $1 \mathrm{H}), 7.41(\mathrm{~d}, J=8.5 \mathrm{~Hz}, 1 \mathrm{H}), 7.39(\mathrm{~d}, J=8.5 \mathrm{~Hz}, 1 \mathrm{H}), 7.29-7.24(\mathrm{~m}$, $4 \mathrm{H}), 4.30(\mathrm{t}, J=7.2 \mathrm{~Hz}, 2 \mathrm{H}), 1.92-1.83(\mathrm{~m}, 2 \mathrm{H}), 1.42-1.19(\mathrm{~m}, 10 \mathrm{H})$, $0.86(\mathrm{t}, J=6.9 \mathrm{~Hz}, 3 \mathrm{H}) .{ }^{13} \mathrm{C} \mathrm{NMR}\left(101 \mathrm{MHz}, \mathrm{CDCl}_{3}\right) \delta 182.35$, $147.51,145.85,141.32,140.92,140.55,137.39,132.11,129.48$, $128.43,126.86,126.27,125.99,124.40,123.79,123.33,122.80$, $120.43,119.20,118.88,118.43$, 109.05, 108.97, 43.26, 31.77, 29.35, 29.15, 29.00, 27.30, 22.59, 14.04.

(E)-5'-(2-(9-Octyl-9H-carbazol-3-yl)vinyl)-2,2'-bithiophene-5carbaldehyde (4). Orange solid, $0.22 \mathrm{~g}$, yield $36 \% ;{ }^{1} \mathrm{H}$ NMR (400 $\left.\mathrm{MHz}, \mathrm{CDCl}_{3}\right) \delta 9.86(\mathrm{~s}, 1 \mathrm{H}), 8.19(\mathrm{~d}, J=1.6 \mathrm{~Hz}, 1 \mathrm{H}), 8.11(\mathrm{~d}, J=$ $7.6 \mathrm{~Hz}, 1 \mathrm{H}), 7.67$ (d, $J=4.0 \mathrm{~Hz}, 1 \mathrm{H}), 7.62(\mathrm{dd}, J=8.4,1.6 \mathrm{~Hz}$, $1 \mathrm{H}), 7.52-7.44(\mathrm{~m}, 1 \mathrm{H}), 7.40(\mathrm{~d}, J=10.5,1 \mathrm{H}), 7.37$ (d, $J=10.5$, $1 \mathrm{H}), 7.28$ (d, $J=3.6 \mathrm{~Hz}, 1 \mathrm{H}), 7.27-7.23(\mathrm{~m}, 3 \mathrm{H}), 7.20$ (d, $J=4.8$ $\mathrm{Hz}, 1 \mathrm{H}), 7.01$ (d, $J=3.6 \mathrm{~Hz}, 1 \mathrm{H}), 4.29$ (t, $J=7.2 \mathrm{~Hz}, 2 \mathrm{H}), 1.97-$ $1.79(\mathrm{~m}, 2 \mathrm{H}), 1.46-1.14(\mathrm{~m}, 10 \mathrm{H}), 0.86(\mathrm{t}, J=6.9 \mathrm{~Hz}, 3 \mathrm{H}) .{ }^{13} \mathrm{C}$ NMR (101 MHz, $\left.\mathrm{CDCl}_{3}\right) \delta 182.89,152.62,146.75,144.39,140.79$, 137.12, 133.01, 129.09, 127.17, 126.09, 124.82, 124.58, 123.36, $122.77,120.46,119.32$, 119.29, 118.97, 117.51, 109.11, 109.04, 43.29, 31.77, 29.35, 29.15, 29.00, 27.30, 22.58, 14.03.

(E)-5'-(2-(9-Octyl-9H-carbazol-3-yl)vinyl)-2, $2^{\prime}: 5^{\prime}, 2^{\prime \prime}$-terthiophene5-carbaldehyde (5). Deep orange solid, $0.37 \mathrm{~g}$, yield 53\%; ${ }^{1} \mathrm{H}$ NMR $\left(400 \mathrm{MHz}, \mathrm{CDCl}_{3}\right) \delta 9.86(\mathrm{~s}, 1 \mathrm{H}), 8.19(\mathrm{~d}, J=1.6 \mathrm{~Hz}, 1 \mathrm{H}), 8.11$ (d, $J=7.6 \mathrm{~Hz}, 1 \mathrm{H}), 7.67(\mathrm{~d}, J=4.0 \mathrm{~Hz}, 1 \mathrm{H}), 7.62(\mathrm{dd}, J=8.4,1.6 \mathrm{~Hz}$, $1 \mathrm{H}), 7.50-7.45(\mathrm{~m}, 1 \mathrm{H}), 7.40(\mathrm{~d}, J=10.5,1 \mathrm{H}), 7.38(\mathrm{~d}, J=10.5,1 \mathrm{H})$, $7.29(\mathrm{~d}, J=3.6 \mathrm{~Hz}, 1 \mathrm{H}), 7.27-7.20(\mathrm{~m}, 3 \mathrm{H}), 7.15(\mathrm{~d}, J=4.8 \mathrm{~Hz}, 1 \mathrm{H})$, $7.14-7.12(\mathrm{~m}, 2 \mathrm{H}), 6.99(\mathrm{~d}, J=3.6 \mathrm{~Hz}, 1 \mathrm{H}), 4.29(\mathrm{t}, J=7.2 \mathrm{~Hz}, 2 \mathrm{H})$, 1.92-1.81 (m, 2H), 1.44-1.18 (m, 10H), $0.86(\mathrm{t}, J=6.9 \mathrm{~Hz}, 3 \mathrm{H}) .{ }^{13} \mathrm{C}$ 
NMR (101 MHz, $\left.\mathrm{CDCl}_{3}\right) \delta 182.35,146.93,144.02,141.58,140.93$, $140.44,139.58,137.33,134.23,134.02,130.42,127.83,127.05$, $126.19,125.94,125.04,124.34,124.34,123.98,123.32,122.83$, $120.44,119.15,118.73,118.70,109.03$, 108.95, 43.27, 31.79, 29.37, 29.17, 29.01, 27.32, 22.60, 14.05.

\section{General procedure for the preparation of dyes I-V}

Aldehyde (0.168 mmol) and BODIPY dye (14 mg, $0.042 \mathrm{mmol})$ were dissolved in dry DMF ( $5 \mathrm{~mL}$ ). Acetic acid (6 drops) and piperidine ( 6 drops) were added, the mixture was flushed with argon and subjected to microwave irradiation $\left(10 \mathrm{~min}, 150{ }^{\circ} \mathrm{C}\right.$, $300 \mathrm{~W}, 150 \mathrm{psi})$. The solvent was removed under reduced pressure and the product was purified by silica gel packed column chromatography (appropriate eluent for the separation of each is described below).

DYE I. Column chromatography $\mathrm{CH}_{2} \mathrm{Cl}_{2}$ : hexane $3: 2, \mathrm{v} / \mathrm{v}$, green solid, yield: $24 \% ;{ }^{1} \mathrm{H}$ NMR (400 $\left.\mathrm{MHz} \mathrm{CDCl}_{3}\right) \delta 8.26$ (s, $2 \mathrm{H}), 8.14(\mathrm{~d}, J=7.6 \mathrm{~Hz}, 2 \mathrm{H}), 7.78(\mathrm{~s}, 2 \mathrm{H}), 7.75(\mathrm{~d}, J=4.4 \mathrm{~Hz}, 1 \mathrm{H})$, 7.44-7.40 (m, 4H), 7.37-7.34 (m, 4H), $7.22(\mathrm{~d}, J=7.6 \mathrm{~Hz}, 2 \mathrm{H})$, $6.91(\mathrm{~s}, 1 \mathrm{H}), 6.62(\mathrm{~s}, 1 \mathrm{H}), 4.25(\mathrm{t}, J=7.2 \mathrm{~Hz}, 4 \mathrm{H}), 2.29(\mathrm{~s}, 3 \mathrm{H}), 2.10$ (s, 6H), 1.85-1.80 (m, 4H), $1.41(\mathrm{~s}, 6 \mathrm{H}), 1.37-1.13(\mathrm{~m}, 20 \mathrm{H}), 0.80$ $(\mathrm{t}, J=6.9 \mathrm{~Hz}, 6 \mathrm{H}) .{ }^{13} \mathrm{C} \mathrm{NMR}\left(101 \mathrm{MHz}, \mathrm{CDCl}_{3}\right) \delta 151.75,140.06$, 139.94, 139.75, 137.46, 136.22, 136.18, 134.65, 131.37, 130.56, $127.84,127.10,124.92,124.60,122.34,122.00,119.74,119.22$, $118.31,116.14,115.74,108.06,107.94,42.29,30.78,28.36$, 28.15, 28.01, 26.31, 21.59, 20.22, 18.71, 13.04, 12.64. HRMS: calcd for $\mathrm{M}-\mathrm{F}+\left(\mathrm{C}_{64} \mathrm{H}_{71} \mathrm{~N}_{4} \mathrm{BF}\right)$ : 925.5750, found: 925.5753 .

DYE II. Column chromatography $\mathrm{CH}_{2} \mathrm{Cl}_{2}$ : hexane $3: 1, \mathrm{v} / \mathrm{v}$, deep green solid, yield: $34 \% ;{ }^{1} \mathrm{H}$ NMR $\left(400 \mathrm{MHz}, \mathrm{CDCl}_{3}\right) \delta 8.20$ $(\mathrm{s}, 2 \mathrm{H}), 7.96(\mathrm{~d}, J=7.6 \mathrm{~Hz}, 2 \mathrm{H}), 7.61(\mathrm{dd}, J=8.6,1.2 \mathrm{~Hz}, 2 \mathrm{H}), 7.57$ $(\mathrm{d}, J=16.0 \mathrm{~Hz}, 2 \mathrm{H}), 7.39-7.24(\mathrm{~m}, 10 \mathrm{H}), 7.21$ (d, $J=8.6 \mathrm{~Hz}, 2 \mathrm{H})$, $7.14(\mathrm{~d}, J=3.8 \mathrm{~Hz}, 2 \mathrm{H}), 7.06(\mathrm{t}, J=7.6 \mathrm{~Hz}, 2 \mathrm{H}), 7.01(\mathrm{~d}, J=3.8 \mathrm{~Hz}$, $2 \mathrm{H}), 6.96(\mathrm{~s}, 2 \mathrm{H}), 6.60(\mathrm{~s}, 2 \mathrm{H}), 4.10(\mathrm{t}, J=7.2 \mathrm{~Hz}, 4 \mathrm{H}), 2.35(\mathrm{~s}, 3 \mathrm{H})$, $2.13(\mathrm{~s}, 6 \mathrm{H}), 1.79-1.71(\mathrm{~m}, 4 \mathrm{H}), 1.45(\mathrm{~s}, 6 \mathrm{H}), 1.27-1.21(\mathrm{~m}, 20 \mathrm{H})$, $0.85(\mathrm{t}, J=6.9 \mathrm{~Hz}, 6 \mathrm{H}) .{ }^{13} \mathrm{C} \mathrm{NMR}\left(101 \mathrm{MHz}, \mathrm{CDCl}_{3}\right) \delta 151.77$, 145.83 , 140.86, 140.79, 140.76, 140.38, 138.59, 137.01, 135.62, $133.09,131.38,131.05,129.36,128.89,128.55,127.98,126.57$, $125.69,124.57,123.29,122.81,120.44,119.06,119.02,118.62$, 118.40, 117.64, 109.03, 108.67, 43.09, 31.79, 29.33, 29.16, 28.94, 27.26, 22.60, 21.23, 19.72, 14.06, 13.63. HRMS: calcd for M - F + $\left(\mathrm{C}_{76} \mathrm{H}_{79} \mathrm{~N}_{4} \mathrm{~S}_{2} \mathrm{BF}\right): 1141.5818$, found: 1141.5822 .

DYE III. Column chromatography $\mathrm{CH}_{2} \mathrm{Cl}_{2}$ : hexane $3: 1, \mathrm{v} / \mathrm{v}$, brown solid, yield: $26 \% ;{ }^{1} \mathrm{H}$ NMR $\left(400 \mathrm{MHz}, \mathrm{CDCl}_{3}\right) \delta 8.21$ (s, $2 \mathrm{H}), 8.13(\mathrm{~d}, J=7.6 \mathrm{~Hz}, 2 \mathrm{H}), 7.64(\mathrm{~d}, J=8.4 \mathrm{~Hz}, 2 \mathrm{H}), 7.61-7.22$ $(\mathrm{m}, 16 \mathrm{H}), 7.19(\mathrm{~d}, J=4.8 \mathrm{~Hz}, 4 \mathrm{H}), 6.97(\mathrm{~s}, 2 \mathrm{H}), 6.60(\mathrm{~s}, 2 \mathrm{H}), 4.29$ $(\mathrm{t}, J=7.2 \mathrm{~Hz}, 4 \mathrm{H}), 2.35(\mathrm{~s}, 3 \mathrm{H}), 2.13(\mathrm{~s}, 6 \mathrm{H}), 1.89-1.85(\mathrm{~m}, 4 \mathrm{H})$, $1.45(\mathrm{~s}, 6 \mathrm{H}), 1.42-1.17(\mathrm{~m}, 20 \mathrm{H}), 0.87(\mathrm{t}, J=6.9 \mathrm{~Hz}, 3 \mathrm{H}) .{ }^{13} \mathrm{C} \mathrm{NMR}$ $\left(101 \mathrm{MHz}, \mathrm{CDCl}_{3}\right) \delta 151.55,147.72,147.64,144.86,144.41$, 144.32 , 140.91, 140.46, 140.15, 139.90, 138.23, 135.56, 135.50, 133.18, 130.40, 128.92, 128.60, 127.85, 125.91, 124.42, 123.32, 122.86, 120.47, 119.72, 119.15, 118.84, 117.76, 109.03, 108.93, $43.25,31.78,29.36,29.16,29.01,27.31,22.59,21.22,19.67$, 14.04, 13.62. HRMS: calcd for $\mathrm{M}-\mathrm{F}+\left(\mathrm{C}_{80} \mathrm{H}_{79} \mathrm{~N}_{4} \mathrm{~S}_{4} \mathrm{BF}\right)$ : 1253.5259, found: 1253.5257 .

DYE IV. Column chromatography toluene : heptane $3: 1, \mathrm{v} / \mathrm{v}$, $\mathrm{CH}_{2} \mathrm{Cl}_{2}$ : hexane $3: 2$, v/v, deep brown solid, yield: $28 \% ;{ }^{1} \mathrm{H}$ NMR $\left(400 \mathrm{MHz}, \mathrm{CDCl}_{3}\right) \delta 8.05(\mathrm{~d}, J=1.2 \mathrm{~Hz}, 2 \mathrm{H}), 8.01(\mathrm{~d}, J=7.6 \mathrm{~Hz}$, $2 \mathrm{H}), 7.48-7.43(\mathrm{~m}, 4 \mathrm{H}), 7.40-7.32(\mathrm{~m}, 2 \mathrm{H}), 7.29(\mathrm{~d}, J=8.2 \mathrm{~Hz}$, 2H), 7.25-7.21 (m, 2H), 7.21-7.13 (m, 4H), 7.08 (d, $J=7.6 \mathrm{~Hz}$, $4 \mathrm{H}), 7.04(\mathrm{~s}, 2 \mathrm{H}), 6.91(\mathrm{~d}, J=3.8 \mathrm{~Hz}, 2 \mathrm{H}), 6.90(\mathrm{~s}, 2 \mathrm{H}), 6.53(\mathrm{~s}, 2 \mathrm{H})$, $4.15(\mathrm{t}, J=7.2 \mathrm{~Hz}, 4 \mathrm{H}), 2.29(\mathrm{~s}, 3 \mathrm{H}), 2.06(\mathrm{~s}, 6 \mathrm{H}), 1.80-1.73(\mathrm{~m}$, $4 \mathrm{H}), 1.46(\mathrm{~s}, 6 \mathrm{H}), 1.33-1.10(\mathrm{~m}, 20 \mathrm{H}), 0.79(\mathrm{t}, J=6.9 \mathrm{~Hz}, 6 \mathrm{H}) .{ }^{13} \mathrm{C}$ NMR $\left(101 \mathrm{MHz}, \mathrm{CDCl}_{3}\right) \delta 140.86,128.91,127.94,125.82,124.38$, 123.24, 122.86, 120.47, 119.06, 118.59, 43.17, 31.87, 29.34, 29.16, 28.97, 27.29, 22.68, 22.59, 19.70, 14.04, 13.62. HRMS: calcd for M $-\mathrm{F}+\left(\mathrm{C}_{84} \mathrm{H}_{83} \mathrm{~N}_{4} \mathrm{~S}_{4} \mathrm{BF}\right):$ 1305.5572, found: 1305.5576 .

DYE V. Column chromatography $\mathrm{CH}_{2} \mathrm{Cl}_{2}$ : hexane $3: 2, \mathrm{v} / \mathrm{v}$, deep brown solid, yield: $30 \% ;{ }^{1} \mathrm{H}$ NMR (400 $\mathrm{MHz}, \mathrm{CDCl}_{3}$ ) $\delta 8.12(\mathrm{~s}, 2 \mathrm{H}), 8.05(\mathrm{~d}, J=7.6 \mathrm{~Hz}, 2 \mathrm{H}), 7.55-7.51(\mathrm{~m}, 4 \mathrm{H}), 7.46-$ $7.42(\mathrm{~m}, 2 \mathrm{H}), 7.35(\mathrm{~d}, J=8.2 \mathrm{~Hz}, 2 \mathrm{H}), 7.31(\mathrm{~d}, J=16 \mathrm{~Hz}, 2 \mathrm{H}), 7.23$ $(\mathrm{d}, J=5.6 \mathrm{~Hz}, 2 \mathrm{H}), 7.18(\mathrm{~d}, J=16 \mathrm{~Hz}, 2 \mathrm{H}), 7.26-7.05(\mathrm{~m}, 18 \mathrm{H})$, $6.97(\mathrm{~s}, 2 \mathrm{H}), 6.94(\mathrm{~d}, J=3.8 \mathrm{~Hz}, 2 \mathrm{H}), 6.60(\mathrm{~s}, 2 \mathrm{H}), 4.17(\mathrm{t}, J=7.2$ $\mathrm{Hz}, 4 \mathrm{H}), 2.35(\mathrm{~s}, 3 \mathrm{H}), 2.13(\mathrm{~s}, 6 \mathrm{H}), 1.84-1.77(\mathrm{~m}, 4 \mathrm{H}), 1.45(\mathrm{~s}, 6 \mathrm{H})$, 1.37-1.19 (m, 20H), $0.86(\mathrm{t}, J=6.9 \mathrm{~Hz}, 6 \mathrm{H}) .{ }^{13} \mathrm{C}$ NMR $(101 \mathrm{MHz}$, $\left.\mathrm{CDCl}_{3}\right) \delta 151.63,143.21,141.62,141.08,140.84,140.28,138.72$, $138.67,137.49,137.34,135.80,135.55,134.74,133.14,131.28$, 129.90, 129.52, 128.94, 128.15, 127.95, 126.24, 125.79, 125.14, 124.37, 124.33, 124.33, 123.22, 122.86, 120.45, 119.03, 118.87, $118.73,118.55,117.68,108.91,108.82,43.14,31.79,29.35$, 29.17, 28.97, 27.29, 22.60, 21.23, 19.72, 14.06, 13.63. HRMS: calcd for $\mathrm{M}-\mathrm{F}+\left(\mathrm{C}_{92} \mathrm{H}_{87} \mathrm{~N}_{4} \mathrm{~S}_{6} \mathrm{BF}\right)$ : 1469.5327, found: 1469.5331 .

\section{Conclusions}

A series of panchromatic D-A-D type dyes consisting of BODIPY, carbazole and thiophenes linkers have been synthesized in microwave - assisted Knoevenagel condensation. The novel materials absorb light in spectral range from 300-800 nm with high molar extinction coefficients (up to $140000 \mathrm{M}^{-1} \mathrm{~cm}^{-1}$ ) and could be considered as perspective light harvesters for photovoltaics.

The most important highlights of our study are:

1. Addition of a thiophene based linkers between BODIPY and carbazole results in the red shift of the spectra.

2. Length of the thiophene - based linker does not have an impact on the shift of the lower energy absorption maxima. Despite the evident shifts in absorption maxima of the components used in the Knoevenagel condensation reaction, the final structures, with thiophene, bithiophene and terthiophene linkers, display similar red - edge absorption. The incorporation of additional thiophene units lowers simultaneously both HOMO and LUMO orbitals thus does not lower the value of energy band gap.

3. The hyperchromic (increase in absorption coefficient) shift of the highest energy band is observed what can be attributed to the enhanced internal charge transfer (ICT) contribution.

4. The longer the linker between BODIPY and carbazole moieties is, the smallest is the influence of carbazole unit on the lowest energy transition of the molecule. For molecules with longer conjugation, the frontier orbitals are localized mostly on BODIPY core and thiophene - based linkers. The electron density located on carbazole is small. It should be noted that 
there is only minimal electron density on terminal benzene ring of the carbazole unit. This feature will prevent an oxidative polymerization typical for carbazole derivatives and hence stabilize the charged redox states of the molecules. ${ }^{37}$

5. Addition of thiophene - based linkers results in almost complete quenching of emission what might be caused by the stronger push-pull effect for systems with elongated conjugation framework.

\section{Acknowledgements}

The research leading to these results has received funding from the People Programme (Marie Curie Actions) of the European Union's Seventh Framework Programme FP7/2007-2013/under REA grant agreement no. 612670. Calculations have been carried out using resources provided by Wroclaw Centre for Networking and Supercomputing (http://wcss.pl), grant no. 126. Funding for this work from the Australian Research Council Centre of Excellence Scheme (Project Number CE 140100012) and support from the Australian National Fabrication Facility is gratefully acknowledged.

\section{Notes and references}

1 M. Vendrell, D. Zhai, J. Cheng Er and Y. Chang, Chem. Rev., 2012, 112, 4391.

2 A. Mishra and P. Bäuerle, Angew. Chem., Int. Ed., 2012, 51, 2020.

3 Z. Zhang and J. Wang, J. Mater. Chem., 2012, 22, 4178.

4 H. Lu, J. Mack, Y. Yanga and Z. Shen, Chem. Soc. Rev., 2014, 43, 4778.

5 Y. Nia and J. Wu, Org. Biomol. Chem., 2014, 12, 3774.

6 N. Boens, V. Leen and W. Dehaen, Chem. Soc. Rev., 2012, 41, 1130.

7 A. Bessetteab and G. S. Hanan, Chem. Soc. Rev., 2014, 43, 3342.

8 L. Sobenina, O. Petrova, K. Petrushenko, I. Ushakov, A. Mikhaleva, R. Meallet-Renault and B. Trofimov, Eur. J. Org. Chem., 2013, 19, 4107.

9 E. Y. Schmidt, N. V. Zorina, M. Y. Dvorko, N. I. Protsuk, K. V. Belyaeva, G. Clavier, R. Méallet-Renault, T. T. Vu, A. I. Mikhaleva and B. A. Trofimov, Chem.-Eur. J., 2011, 17, 3069.

10 T. Rousseau, A. Cravino, E. Ripaud, P. Leriche, S. Rihn, A. De Nicola, R. Ziessel and J. Roncali, Chem. Commun., 2010, 46, 5082 .

11 T. Bura, N. Leclerc, S. Fall, P. Lévêque, T. Heiser, P. Retailleau, S. Rihn, A. Mirloup and R. Ziessel, J. Am. Chem. Soc., 2012, 134, 17404.

12 A. Sutter, P. Retailleau, W.-C. Huang, H.-W. Lin and R. Ziessel, New J. Chem., 2014, 38, 1701.

13 J. Liao, Y. Xu, H. Zhao, Y. Wang, W. Zhang, F. Peng, S. Xie and X. Yang, RSC Adv., 2015, 5, 86453.
14 D. Zhang, V. Martín, I. García-Moreno, A. Costela, M. Eugenia Pérez-Ojedab and Y. Xiao, Phys. Chem. Chem. Phys., 2011, 13, 13026.

15 X. Zhang, Y. Xiao, J. Qi, J. Qu, B. Kim, X. Yue and K. D. Belfield, J. Org. Chem., 2013, 78, 9153.

16 P. E. Kesavan and I. Gupta, Dalton Trans., 2014, 43, 12405. 17 T. Wood and A. Thompson, Chem. Rev., 2007, 107, 1831.

18 E. Palao, A. Agarrabeitia, J. Banuelos-Prieto, T. Arbeloa Lopez, I. Lopez-Arbeloa, D. Armesto and M. Ortiz, Org. Lett., 2013, 15, 4454.

19 V. Promarak, A. Punkvuang, T. Sudyoadsuk, S. Jungsuttiwong, S. Saengsuwan, T. Keawin and K. Sirithip, Tetrahedron, 2007, 63, 8881.

20 T. Khanasa, N. Prachumrak, R. Rattanawan, S. Jungsuttiwong, T. Keawin, T. Sudyoadsuk and V. Promarak, J. Org. Chem., 2013, 78, 6702.

21 D. Collado, J. Casado, S. Rodríguez Gonzélez, J. T. López Navarrete, R. Suau, E. Perez-Inestrosa, T. M. Pappenfus and M. M. M. Raposo, Chem.-Eur. J., 2011, 17, 498.

22 X. Zhang, H. Yu and Y. Xiao, J. Org. Chem., 2012, 77, 669.

23 Y. Chen, J. Zhao, H. Guo and L. Xie, J. Org. Chem., 2012, 77, 2192.

24 R. Rybakiewicz, P. Gawrys, D. Tsikritzis, K. Emmanouil, S. Kennou, M. Zagorska and A. Pron, Electrochim. Acta, 2013, 96, 13.

25 P. Bujak, I. Kulszewicz-Bajer, M. Zagorska, V. Maurel, I. Wielgus and A. Pron, Chem. Soc. Rev., 2013, 42, 8895.

26 A. Pron, P. Gawrys, M. Zagorska, D. Djurado and R. Demadrille, Chem. Soc. Rev., 2010, 39, 2577.

27 R. Y. Lai and A. J. Bard, J. Phys. Chem. B, 2003, 107, 5036.

28 J. A. E. H. van Haare, E. E. Havinga, J. L. J. van Dongen, R. A. J. Janssen, J. Cornil and J.-L. Bredas, Chem.-Eur. J., 1998, 4, 1509.

29 X. Zhang, Y. Zhang, L. Chen and Y. Xiao, RSC Adv., 2015, 5, 32283.

30 A. N. Kursunlu, E. Sahin and E. Guter, RSC Adv., 2015, 5, 5951.

31 M. A. H. Alamiry, A. C. Benniston, J. Hagon, T. P. L. Winstanley, H. Lemmetyinen and N. V. Tkachenko, RSC Adv., 2012, 2, 4944.

32 B. C. Popere, A. M. Della Pelle, A. Poe, G. Balaji and S. Thayumanavan, Chem. Sci., 2012, 3, 3093.

33 M. Scheuble, M. Goll and S. Ludwigs, Macromol. Rapid Commun., 2015, 36, 115.

34 J.-L. Bredas, Mater. Horiz., 2014, 1, 17.

35 J.-F. Morin, N. Drolet, Y. Tao and M. Leclerc, Chem. Mater., 2004, 16, 4619-4626.

36 R. Rossi, A. Carpita, M. Ciofalo and J. Houben, Gazz. Chim. Ital., 1990, 120, 793.

37 K. Karon and M. Lapkowski, J. Solid State Electrochem., 2015, 19, 2601. 